\title{
Whole animal studies using tracer kinetics
}

By D. S. Kronfeld and C. F. Ramberg, University of Pennsylvania, Kennet Square, $P A 1934^{8}$ USA

Five general problems of kinetic analysis will be illustrated in this paper, mainly with the aid of simulations based on previously published models of glucose kinetics in cows. These simulations and model solutions were obtained with the aid of the SAAM27 computer program (Berman \& Weiss, 1978) in the conversational mode, CONSAM (Boston et al. 1979).

\section{Linearity and nonlinearity}

The general approach of tracer kinetics is to observe responses or outputs, $y(t)$, of a system to known stimuli or inputs, $x(t)$. A tracer should not perturb the system so responses should be linear; if $x_{1} \rightarrow y_{1}$ and $x_{2} \rightarrow y_{2}$, then $k_{1} x_{1}+k_{2} x_{2} \rightarrow k_{1} y_{1}+$ $k_{2} y_{2}$. Linearity greatly simplifies mathematical analysis and this is the main advantage of using tracers as inputs rather than loads of tracee or mother substance (Fig. I). Use of an input of tracee which is a nutrient or metabolite may disturb homoeostasis and lead to nonlinear responses. Ultimately, we want to understand regulation in terms of nonlinear models, but this goal is approached through the progressive interplay of model building and experimentation which involves tracers and linear responses (Berman, 1969; Ramberg, 1974).

\section{Fitting exponentials}

Exponential equations are often fitted to tracer response curves because they usually describe data on biological rate functions and they can be readily employed to calculate flow rates and the smallest compartment of tracee defined by the data. Exponential descriptions of responses may be consistent with other physiological information about the system, hence constitute physiological models. Alternatively, if sums of exponentials do not appear to represent a physical construct of the system, they may be readily transformed or mapped into some related construct which does; this is the situation with the glucose system in cows (Kronfeld et al. 1971; Horsfield et al. 1974).

The number of exponentials which is the minimum necessary to fit a curve is illustrated by best fits of two and three exponentials to data from a dog (Fig. 2). Systematic deviations between observed and predicted points occurred with two exponentials but not three. The sum of squares of the deviations between observed and calculated values was three times greater with two exponentials than with three thus three were necessary.

Also, three exponentials were sufficient, because fitting four failed to improve the sum of squares and greatly increased the average fractional standard deviation of kinetic parameters from 0.18 to 480000000 .

$0029-6651 / 8 \mathrm{r} / 4013-4805 \$ 01.00$ (C) 198I The Nutrition Society 


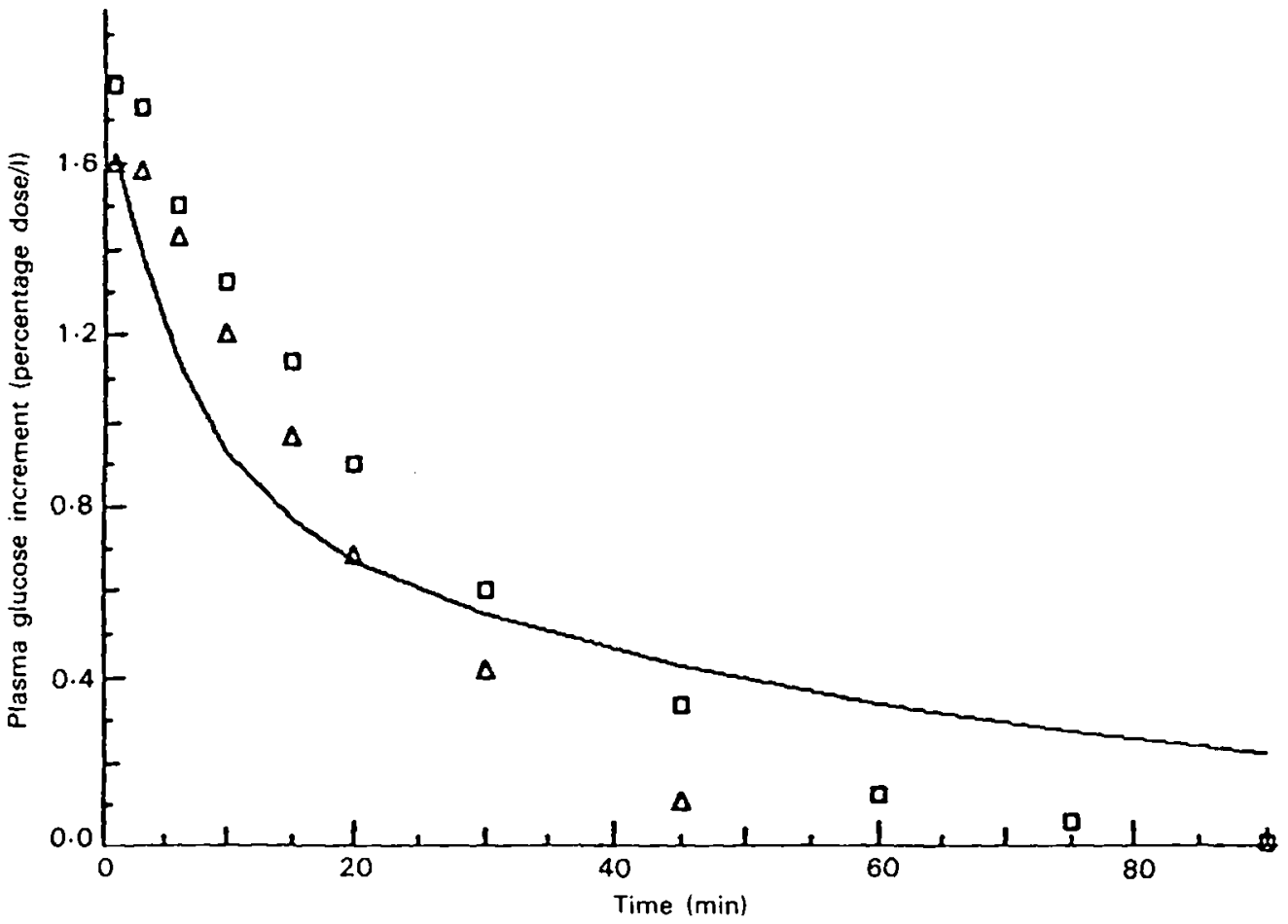

Fig. r. Nonlinearity of plasma glucose responses during intravenous glucose tolerance tests in a cow demonstrated by comparison with each other and with a tracer response. The cow was given two doses of glucose, one double the other, and plasma glucose concentration was monitored for $90 \mathrm{~min}$. The two tests were compared by expressing increments as percentage dose/l plasma; the smaller dose $(\Delta ; 0.2 \mathrm{mg}$ glucose $/ \mathrm{kg})$ was cleared more rapidly than the larger $(\square ; 0.4 \mathrm{mg}$ glucose $/ \mathrm{kg}$ ). The two responses were not superimposable upon one another, and both differed from the response generated by a linear model of ${ }^{14} \mathrm{C}$ glucose kinetics (Kronfeld et al. 1971; Kronfeld, 1977).

\section{Observational period}

Differential equations which describe tracer responses (e.g. plasma glucose specific activity plotted against time after a single injection of labelled glucose) must be integrated from time zero to infinity in order to obtain the area subtended by the curve and its reciprocal, turnover rate. This requires theoretically that kinetic coefficients must be constant, i.e. the system must be in a steady state. In practice, the requirement of a steady state is often not satisfied strictly but, fortunately, the estimation of flow rate appears to be a robust method (Wrenshall et al. $196 \mathrm{I})$. In practice, also, the response should be observed from the first to the last measurable change, e.g. from as soon as possible after time zero to the final slope following a single input of tracer or to a true asymptotic value during a constant infusion.

Observational periods confined to final slopes of curves were used by pioneers in glucose and calcium kinetics and are used today in studies of other systems, e.g. cholesterol kinetics. This limitation overestimates turnover rate and, in the case of 


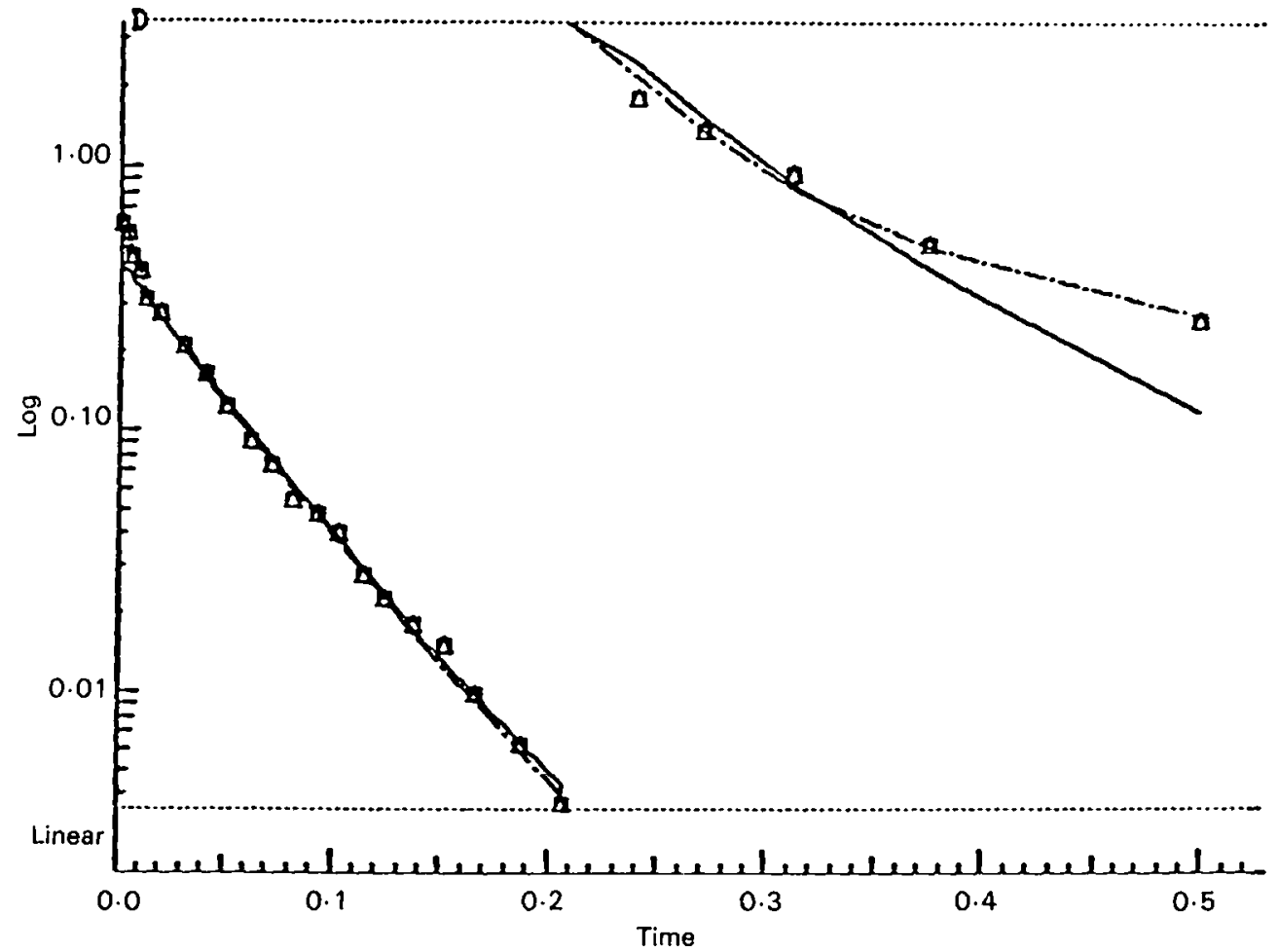

Fig. 2. Systematic deviations (first four points, last three points, and fourth to eighth last points) in fit of two exponential terms (- - ) but not three $\left(-.-{ }_{-}\right)$demonstrates that three terms are the minimum necessary. The data are plasma glucose specific activities following intravenous injection of $\left[6-{ }^{3} \mathrm{H}\right] \mathrm{glucose}$ into a dog.

calcium, rates of deposition and removal from bone. Overestimates obtained in this way for glucose kinetics were soon recognized but then wrongfully attributed to the mode of tracer administration (Steele et al. 1956) instead of the limited observational period (Kronfeld et al. 1971).

The next developments were attempts at choosing a time interval which avoided incomplete mixing initially and recycling later (Steele $e t$ al. 1956) or which yielded a glucose space corresponding to extracellular volume (e.g. Kronfeld \& Simesen, 1961; Judson \& Leng, 1972). This latter objective was also sought by adjustment of the prime:infusion value (Steele et al. 1956; Bergman, 1963; White et al. 1969). In both cases, monoexponential analysis was applied arbitrarily to a limited observational period (c.p. Steele et al. 1956 and Kronfeld et al. 1971).

Inappropriate use of monoexponential analysis has subsided, but use of a limited observational period persists. We have illustrated the consequent error by applying multiexponential analysis over the time interval 30 to $300 \mathrm{~min}$, following single injections of tracer glucose into cows in five physiological conditions (Table 1 ). Two exponentials were necessary and sufficient to fit this limited part of the curve in each case. Systematic deviations developed before and after the limited interval (Fig. 3). The extent of these deviations varies from one physiological status to the 
next, i.e. the errors in estimates of pool size and turnover rate are not systematic (Table I).

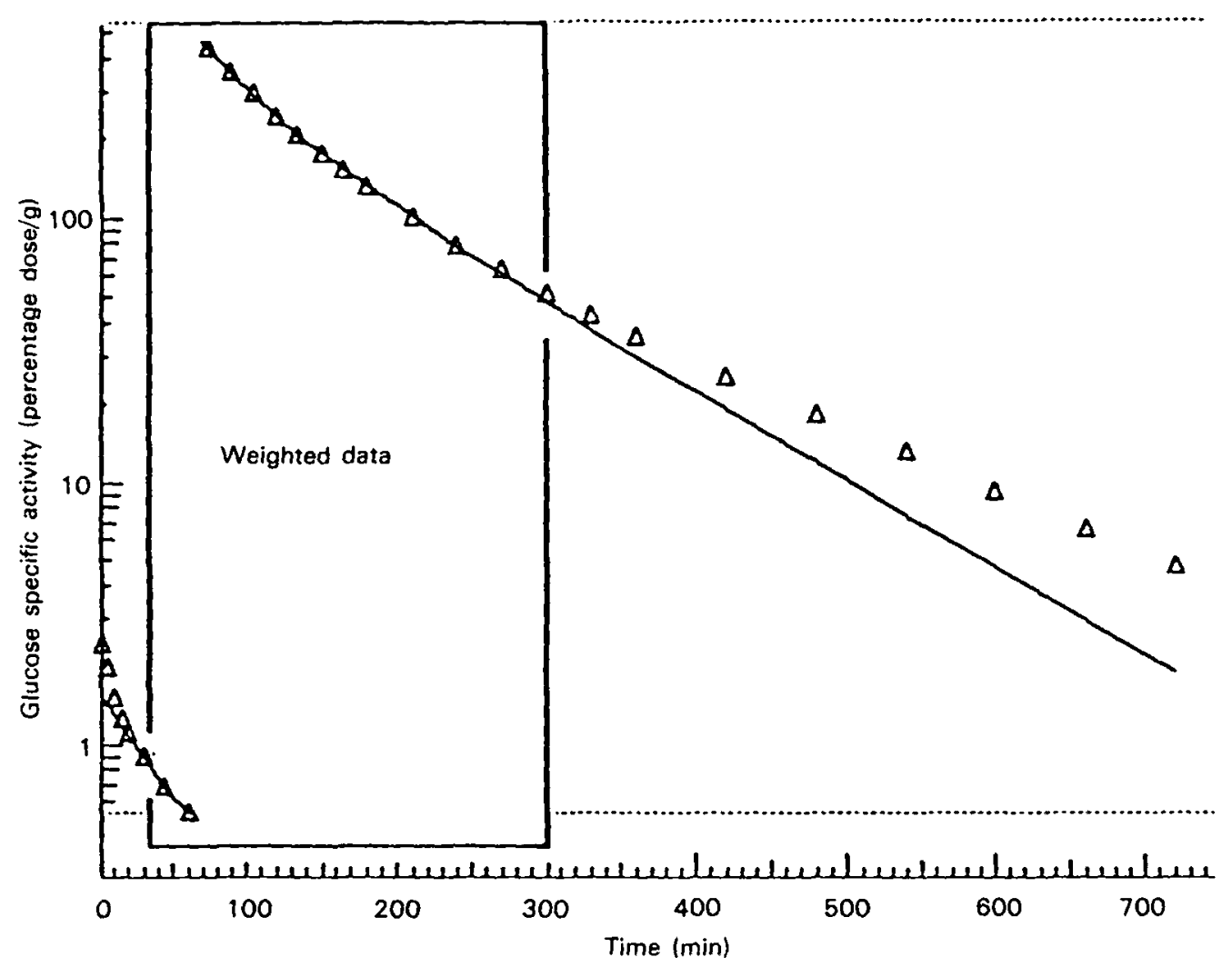

Fig. 3. Restriction of multiexponential analysis to a limited observational period may be simulated by assigning zero weight to points outside that interval. The best fit to the weighted data may be extrapolated, and here the predicted curve (___ $)$ deviates systematically from the observed data $(\Delta)$. Use of the arbitrarily limited observational period usually leads to underestimates of area subtended by the curve and of specific activities at time zero, hence to overestimates of glucose turnover rate and, especially, glucose pool size (see Table I).

Table 1. Effect of observational time period on values calculated for $\left[{ }^{14} \mathrm{C}\right]$ glucose kinetics in cows

Time period (min) ...
Treatment
Fasting
Dexamethasone
Insulin
Normal
Ketotic

\begin{tabular}{cccc}
$\begin{array}{c}\text { Initial pool size }(g) \\
30-300^{\circ}\end{array}$ & \multicolumn{2}{c}{ Turnover rate $(\mathrm{g} / \mathrm{min})$} \\
& $2-720 \dagger$ & $30-300^{\circ}$ & $\mathbf{2 - 7 2 0}$ \\
45 & 21 & 0.43 & 0.36 \\
98 & 63 & 0.39 & 0.70 \\
49 & 25 & 1.01 & 0.83 \\
64 & 35 & 1.05 & 0.87 \\
64 & 29 & 1.40 & 1.27
\end{tabular}

-Fit with 2 term exponential equation.

†Fit with 3 term exponential equation. 
Responses to a tracer are linear. It follows that if the response to one input of tracer is known, the response to any other input may be calculated by convolution (Meier \& Zierler, 1954; Brownell et al. 1968). The identity of the area subtended by a curve following an instantaneous injection with the asymptotic value attained during a constant infusion was proven with the aid of the convolution integral by Meier \& Zierler (1954) in the blood flow field just two years before primed infusions of tracer glucose were advanced as superior to single injections (Steele et al. 1956). The relationship of these modes of tracer administration is illustrated in Fig. 4, and the effect of varying the ratio of the priming injection $(P)$ :infusion rate (I) is shown in Fig. 5. These curves were generated by a linear model of tracer glucose kinetics in lactating cows (Kronfeld et al. 1971; Kronfeld, 1977). The same model may be used to determine the P:I ratio which will estimate turnover rate with the least error (Fig. 6). The model generates the response to a given I, then the asymptotic value is used to fix a plateau for a chosen interval, 150 to $300 \mathrm{~min}$ in this case. The SAAM program then tests a series of values of $P$ and determines the

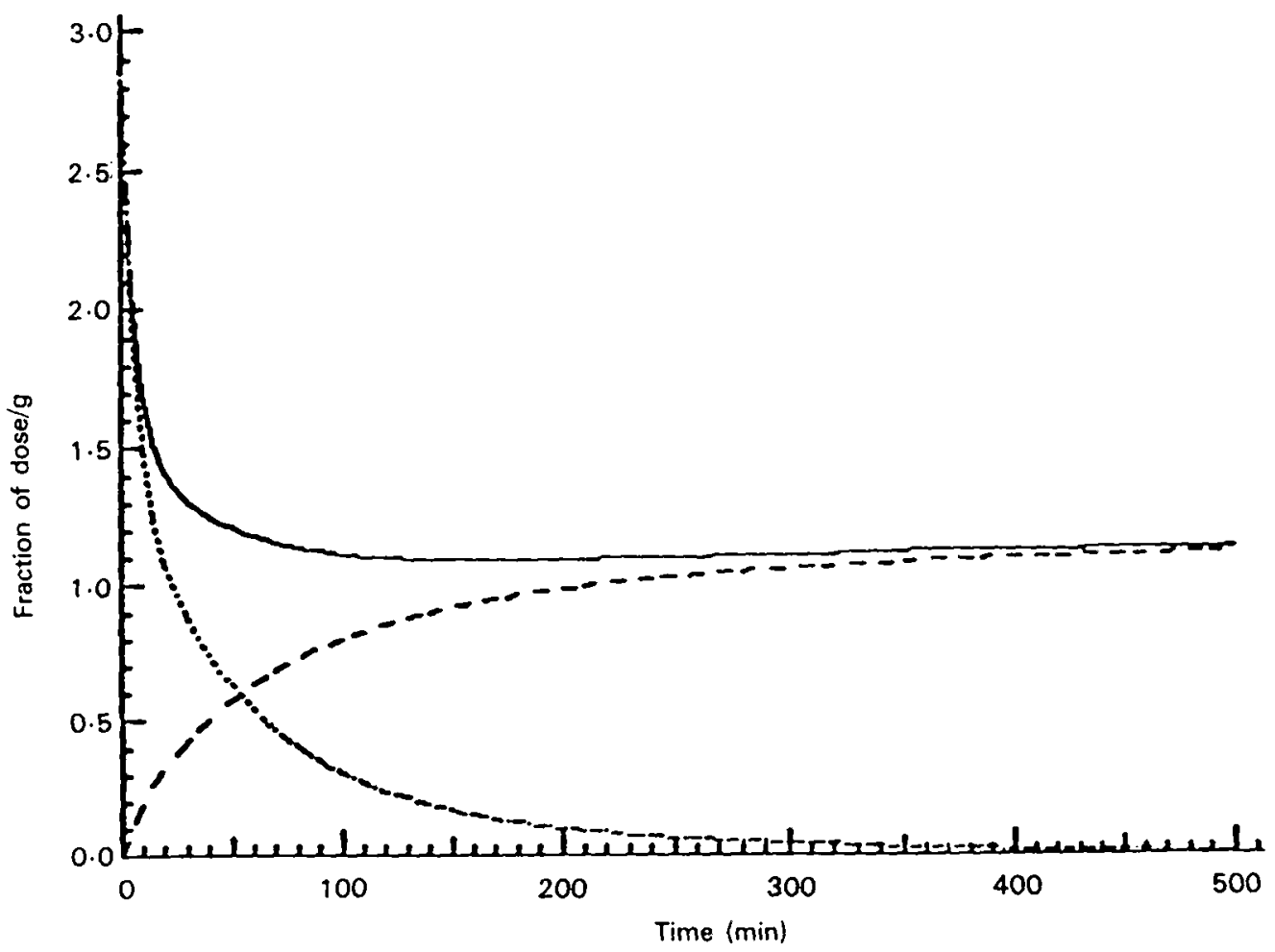

Fig. 4. The response of plasma glucose specific activity during a primed infusion of tracer is the sum of the two component responses, one following the prime, the other during the infusion (...) prime only, (- - - ) infusion only, (- - ) prime + infusion. If any one of these responses is determined experimentally, the others may be calculated using a linear model such as the one shown here which simulates responses of the glucose system in normal lactating cows. The prime dose is $100 \times$ infusion rate. 


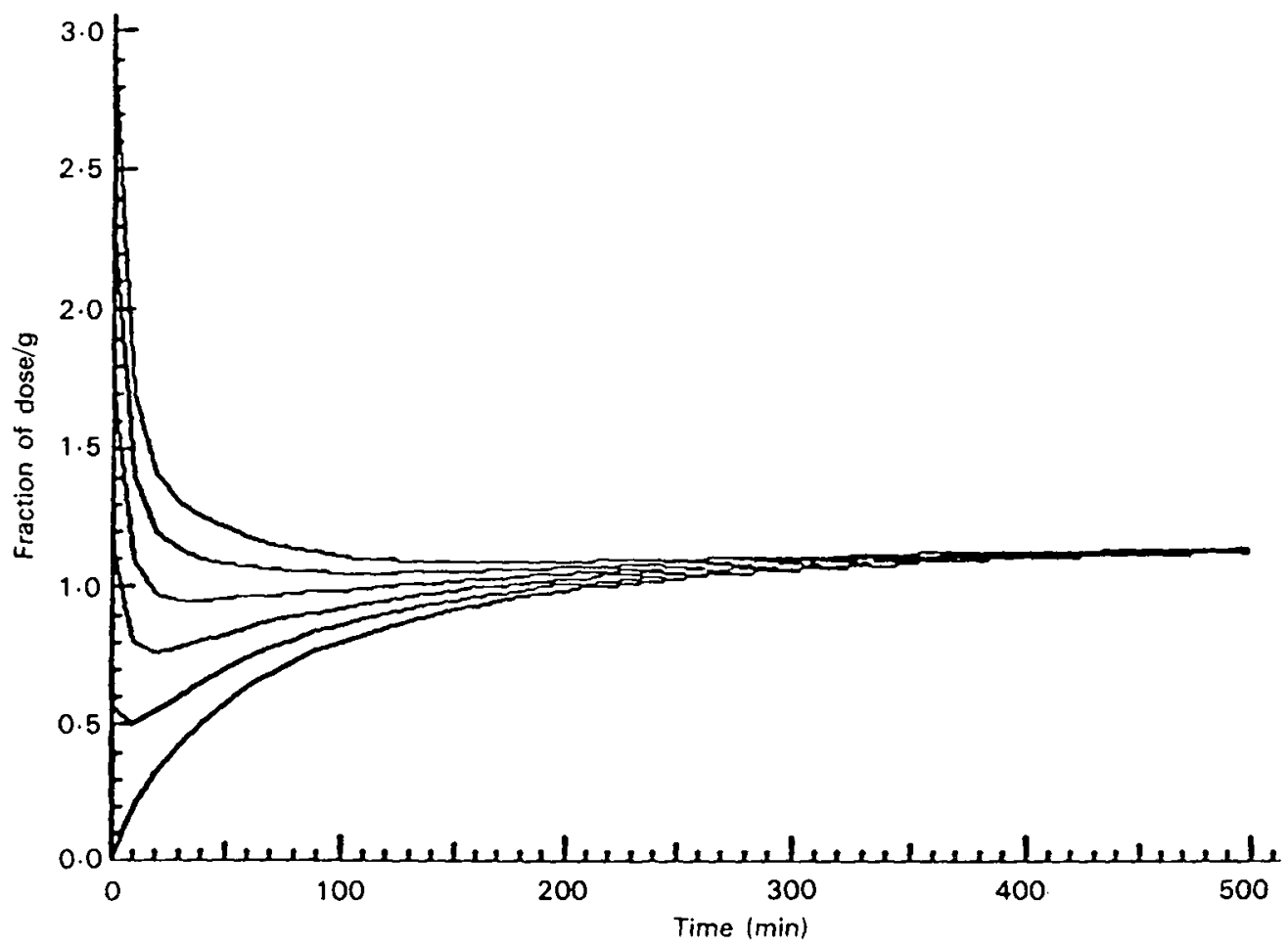

Fig. 5. The linear model of the glucose system in normal, lactating cows was used to generate a set of responses to a series of P:I values. The arbitrarily chosen $P$ :I value has a marked effect on the response in the early part of the experiment. The prime doses used were $0,20,40,60,80$ and $100 \times$ infusion rate.

one which fits best the four points which represent the plateau (Fig. 6). For lactating cows, the optimal P:I value is $144: \mathrm{r}$.

The best $P: I$ for lactating cows may not be the best $P: I$ for other conditions. Estimates of glucose turnover based on a P:I value of $144:$ I are compared to actual average glucose turnovers for five physiological conditions (Fig. 7). The errors appear to be reasonably small when samples are taken between $150-300 \mathrm{~min}$ after the priming dose. Optimal P:I values may be determined for all five conditions (Fig. 8); they vary from 216:1 for starved cows to 103:I for cows which have spontaneous ketosis. We have shown previously that inappropriate P:I ratios lead to difficulties in analysis of data from starved or spontaneously ketotic cows (Kronfeld et al. 1971).

The widespread use of primed infusions of tracer following Steele et al. (1956) revealed a lack of understanding of its limitations. Monoexponential analysis was combined with a limited observational period and a single P:I ratio for various conditions. The limit of $180 \mathrm{~min}$ was chosen because 'values subsequent to $\mathrm{r} 80 \mathrm{~min}$ have shown a tendency to be too high because of recycling' (Steele $e t$ al. 1956). Thus the attainment of a true asymptotic value, which would have determined irreversible loss, was deliberately eschewed. A 'true turnover of 


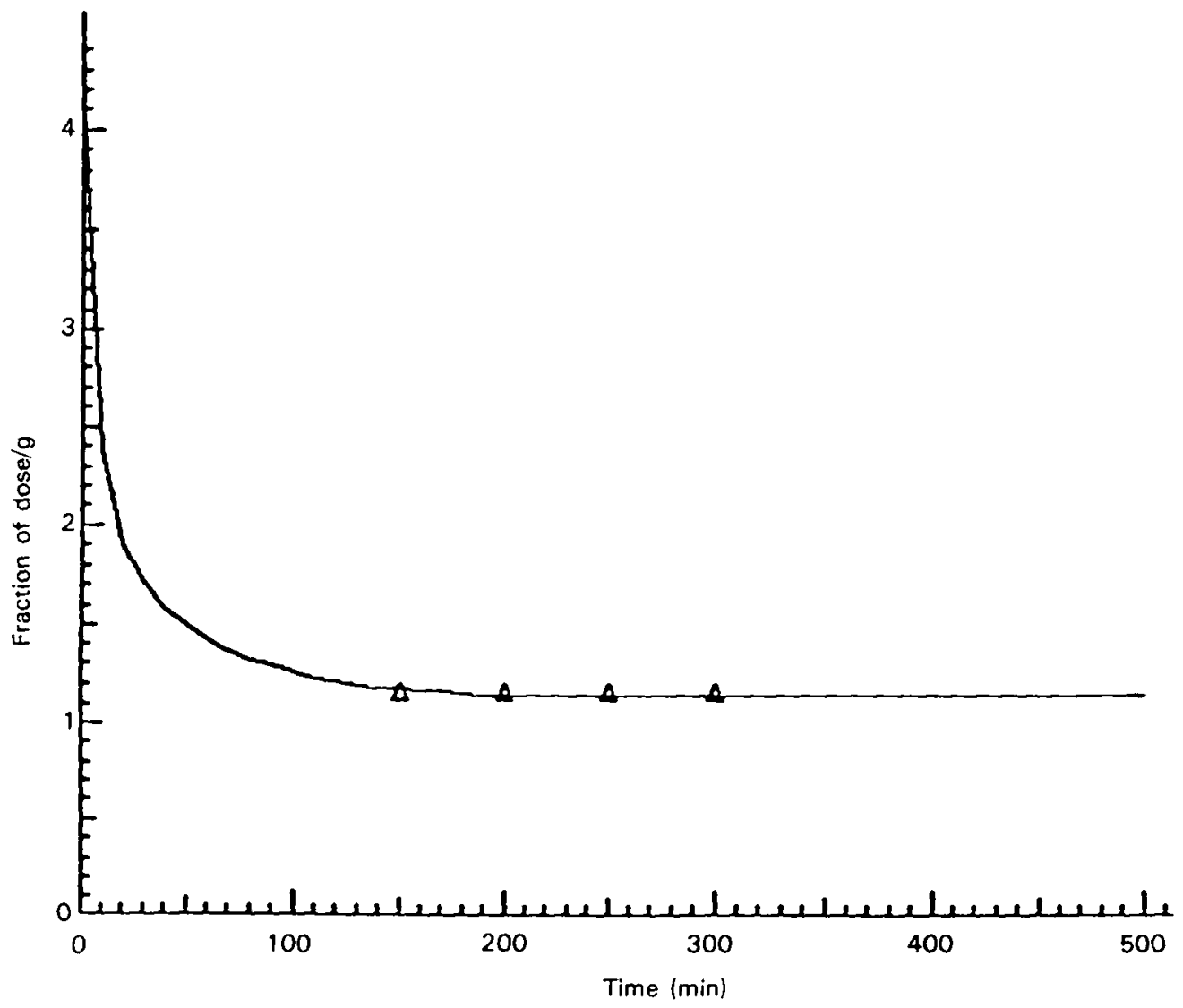

Fig. 6. The best fitting response to a previously determined plateau (or asymptotic value), plotted here as four points $(\Delta)$ over the time interval $15^{0-300 ~ m i n ~ w a s ~ o b t a i n e d ~ b y ~ t h e ~ l i n e a r ~ m o d e l ~ w h e n ~}$ the $P: I$ value was $144: 1$.

glucose' (Bergman et al. 1970) was being sought, apparently the combination of irreversible loss and recycling, and it was being underestimated by about $15 \%$ (Steele et al. 1968; Bergman et al. 1970) by a method which when applied properly would measure irreversible loss only.

\section{Recycling and re-entry}

Recycling may be defined as the return of tracer back into the glucose pool from glucose derivatives (Fig. 9). Re-entry is the return of tracer back into the initial smallest compartment of glucose which can be determined from the data (Gurpide \& Mann, 1970). In the case of our three compartment model of the glucose system (Kronfeld, 1977), re-entry comprises recycling plus the flow returning from the second compartment within the glucose pool (Fig. 9). System, pool and compartment are used here in accordance with definitions proposed by Brownell et al. (1968).

Re-entry was defined by Gurpide \& Mann (1970) in terms of their ' $n$-pool' approach. Their procedures determine the smallest and largest masses that can be 


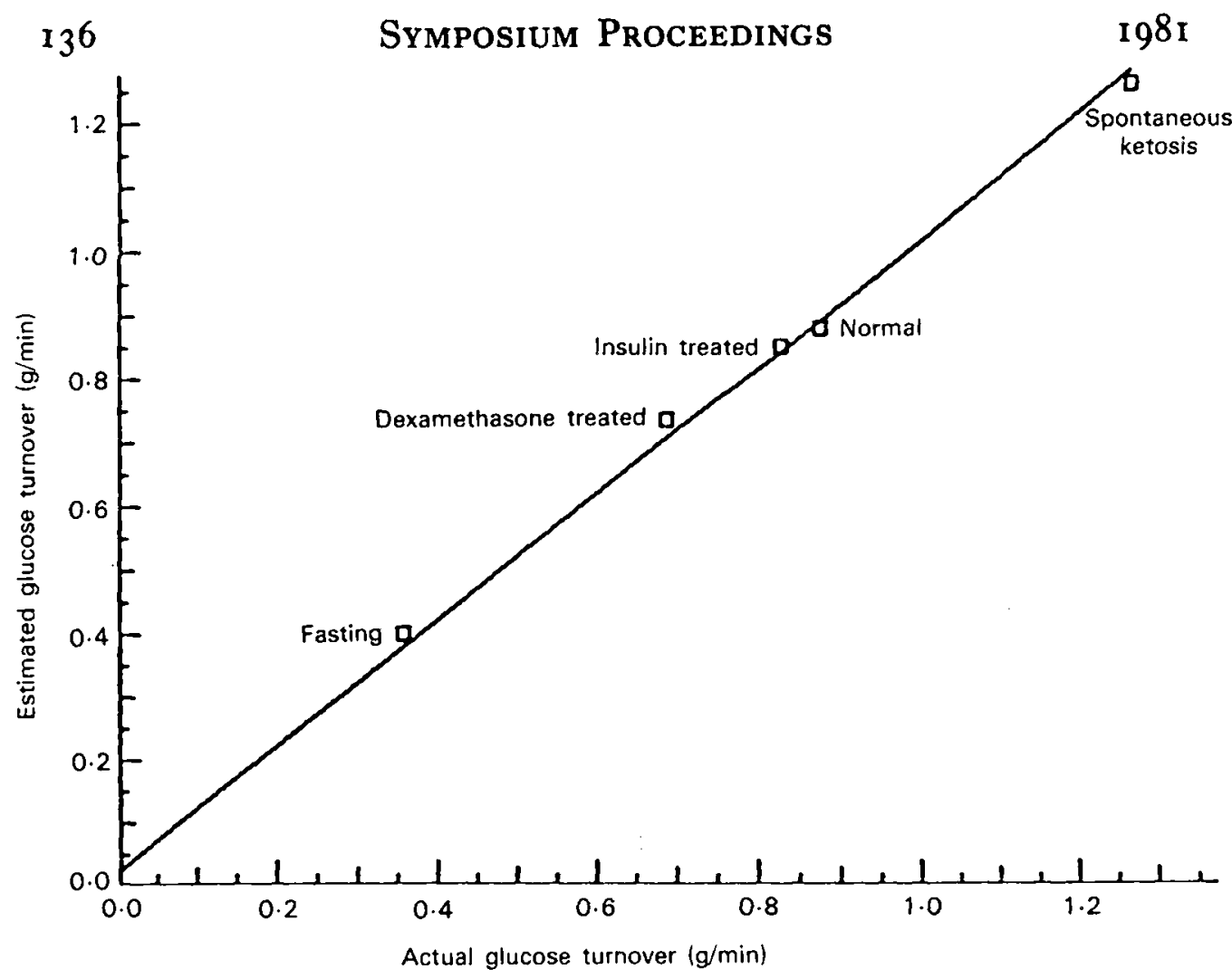

Fig. 7. Estimated glucose turnover rates were calculated from the mean specific activity from 150-300 min during a primed infusion (P:I value $144: 1$ ) and compared to actual glucose turnover rates for cows fasted, treated with insulin or dexamethasone, lactating normally, or affected by spontaneous ketosis $(y=0 \cdot 26+0.98 x)$.

calculated from the data, the replacement rate, and re-entry of tracer back into the smallest compartment. Similar variables have been calculated by Katz et al. (1974), but these workers applied the word recycling instead of re-entry. Nomenclature was further confused by the claim that the proposed analysis was noncompartmental when it required attainment of a final slope or asymptotic value which, in essence, does assume a structure for the system.

Recycling has been estimated by three main approaches; compartmental analysis, randomization of ${ }^{14} \mathrm{C}$ from specific positions in glucose, and comparison of responses to simultaneously administered ${ }^{3} \mathrm{H}$ - and ${ }^{14} \mathrm{C}$-glucose. We have applied the minimal difference postulate (Berman, 1963) to plasma disappearance curves of $\left[{ }^{3} \mathrm{H}\right] g l u c o s e$ and $\left[{ }^{14} \mathrm{C}\right]$ glucose (Kronfeld, 1977 ). When the kinetic parameter, $k_{13}$, which represents recycling was allowed to differ between the responses of the two tracers, and all other parameters were constrained to the same value for both tracers, reasonably good fits were obtained (FSD, $4-24 \%$ ). Systematic deviations occurred when this test was applied to any other parameter in the model, so the observed difference between responses of $\left[{ }^{3} \mathrm{H}\right]$ glucose and $\left[{ }^{14} \mathrm{C}\right]$ glucose is described by a difference in the one parameter which represents recycling. Systematic 


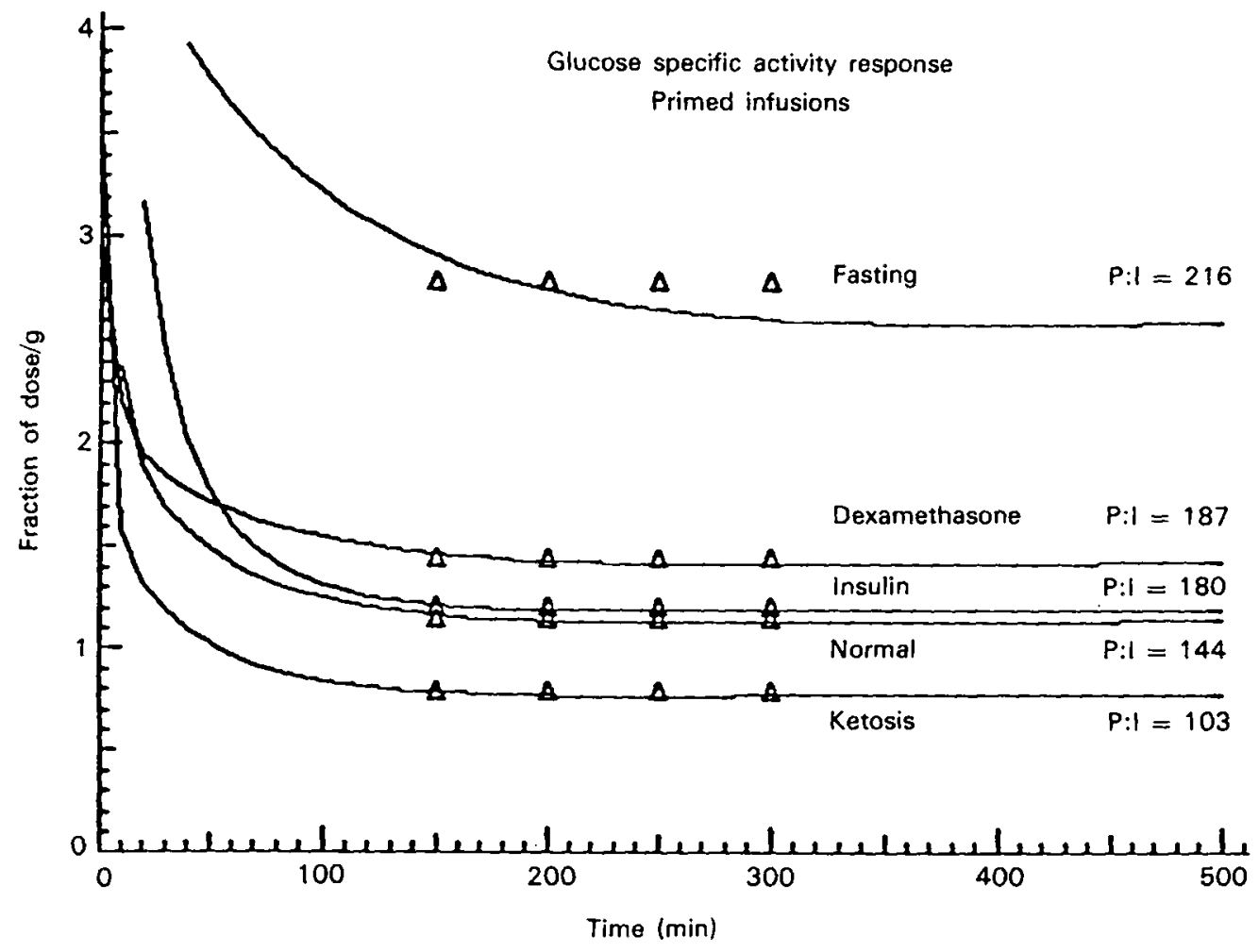

Fig. 8. The optimal P:I value was determined for cows in five conditions by means of linear models based on average responses of plasma glucose specific activities of cows in those conditions (Kronfeld et al. 1971; Kronfeld, 1977). The 'best' P:I value varied inversely with the turnover rate.

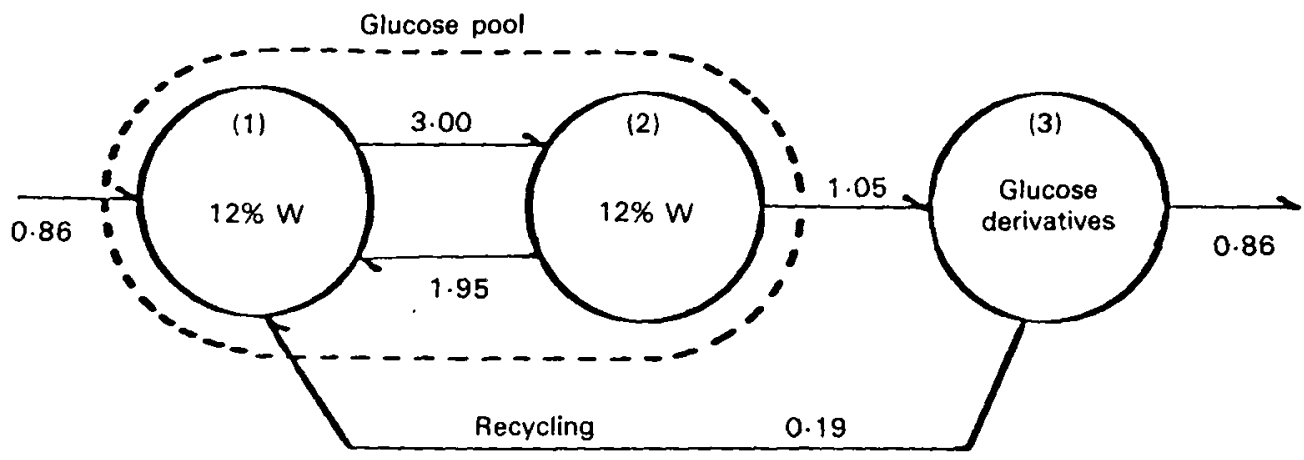

Fig. 9. Schematic representation of recycling and re-entry in terms of a three compartment model of the glucose system. The glucose pool comprises compartments (1) and (2). The outflow from this pool, $1.05 \mathrm{~g} / \mathrm{d}$, goes to compartment (3), which is so large that it must consist of derivatives and associated substances. Recycling is represented by the flow, $0.19 \mathrm{~g} / \mathrm{min}$, from compartment (3) to (I). Re-entry consists of recycling plus the flow from compartment (2) to (I), I.95 g/d, a total of $2 \cdot 14 \mathrm{~g} / \mathrm{d}$ for re-entry. 
deviations also occurred when the parameter which represents recycling of $\left[{ }^{3} \mathrm{H}\right.$ ]glucose was constrained to be zero. This result is not consistent with the assumption that ${ }^{3} \mathrm{H}$ does not recycle at all (Katz et al. 1974). The kinetic analysis proposed by Katz et al. (1974) neglects information inherent in the shape of the curves of $\left[{ }^{3} \mathrm{H}\right]$ glucose and $\left[{ }^{14} \mathrm{C}\right]$ glucose specific activities plotted against time, thus does not allow a test of their assumption that ${ }^{3} \mathrm{H}$ does not recycle. The biochemical basis of the assumption that no ${ }^{3} \mathrm{H}$ recycles is reviewed elsewhere (Judson \& Leng, 1972; Katz et al. 1974).

\section{Conclusion}

Some problems of tracer methodology recur repeatedly. The first four examples discussed here are readily amenable to solution, but clashes of nomenclature and assumptions arising from independent avenues of investigation, as in the last problem, seem likely to persist.

Costs of disposal of radioisotopes are rising prohibitively, so attention is returning to nonlinear tests that involve tangible doses of nutrients and metabolites (Fig. I). There is more hope for the rigorous mathematical analysis of these tests because linear tracer responses are already known for many systems, including glucose, and because computer aids, such as the SAAM Program, are becoming more accessible and easier to use.

\section{REFERENCES}

Bergman, E. N. (1963). Am. Y. Physiol. 204, 147.

Bergman, E. N., Katz, M. L. \& Kaufman, C. F. (1970). Am. F. Physiol. 219, 785.

Berman, M. (1963). f. theoret. Biol. 4, 229.

Berman, M. (1969). FEBS Letters $2 \mathrm{~S}_{5} 6$.

Berman, M. \& Weiss, M. F. (1978). SAAM27, DHEW Publication No. (NIH) 78-180.

Washington, DC: US Government Printing Office.

Boston, R. C., Grief, P. C. \& Berman, M. (1979). CONSAM Instruction Set, Laboratory of Theoretical Biology, National Cancer Institute, Bethesda, MD.

Brownell, G. L., Berman, M. \& Robertson, J. S. (1968). Int. F. appl. Radiat. Isotopes 19249.

Gurpide, E. \& Mann, J. (I970). F. clin. Endocr. Metab. 30, 707.

Horsfield, S., Infield, J. M. \& Annison, E. F. (1974). Proc. Nutr. Soc. 33, 9.

Judson, G. A. \& Leng, R. A. (1972). Aust. F. biol. Sci. 25 I313.

Katz, J., Rostami, H. \& Dunn, A. (1974). Biochem. Э. 142, 161.

Kronfeld, D. S. (1977). Fedn Proc. Fedn Am. Socs exp. Biol. 36, 259.

Kronfeld, D. S. \& Raggi, F. (1964). Am. J. Physiol. 206, 109.

Kronfeld, D. S., Ramberg, C. F. \& Shames, D. M. (1971). Am. Y. Physiol. 220, 886.

Kronfeld, D. S. \& Simesen, M. G. (1961). Cornell Vet. 51, $47^{8}$.

Meier, P. \& Zierler, K. L. (1954). F. appl. Physiol. 6, 731.

Ramberg, C. F. (1974). Fedn Proc. Fedn Am. Socs exp. Biol. 33, I83.

Steele, R., Wall, J. S., de Bodo, R. C. \& Altszuler, N. (1956). Am. F. Physiol. I87, 5.

Steele, R., Winkler, B., Rathgeb, I., Bjerknes, C. \& Altszuler, N. (1968). Am. Y. Physiol. 2 14, 313.

White, R. G., Steel, J. W., Leng, R. A. \& Luick, J. R. (1969). Biochem. J. x14, 203.

Wrenshall, G. A., Hetenyi, G. \& Best, C. H. (1961). Can. Y. Biochem. Physiol. 39, 267. 